\title{
Morphological Study of Adult Male Worms of Schistosoma mansoni Sambon, 1907 by Scanning Electron Microscopy
}

\author{
José Roberto Machado-Silva/ ${ }^{1}{ }^{+}$, Reinalda Marisa Lanfredi*/2, \\ Delir Corrêa Gomes**/2
}

\begin{abstract}
Departamento de Patologia e Laboratórios, Faculdade de Ciências Médicas, UERJ, Rua Teodoro da Silva 48/5 andar, 20560-001 Rio de Janeiro, RJ, Brasil *Laboratório de Helmintologia, Programa de Biologia Celular e Parasitologia, Instituto Carlos Chagas Filho, CCS, Bloco G, UFRJ, Cidade Universitária, 21949-900 Rio de Janeiro, RJ, Brasil **Laboratório de Helmintos Parasitos de Vertebrados, Departamento de Helmintologia, Instituto Oswaldo Cruz, Av. Brasil 4365, 21045-900 Rio de Janeiro, RJ, Brasil
\end{abstract}

Tubercles, spines and sensory receptors are the most studied structures of adult male worms of Schistosoma mansoni isolated in other countries. The purpose of this investigation was to properly define these structures in Brazilian worms. Specimens 7-8 weeks after infection were recovered from albino SW mice and from a wild rodent (Nectomys squamipes) and processed for scanning electron microscopy studies. Photomicrographs of the anterior region with the aspects related to the outer and inner regions of both suckers were considered. The ventral portion of the middle region was represented by the anterior of gynaecophoric canal while the dorsal surface was studied in its ventral and dorsal regions mainly focusing the aspect of the tubercles, spines and sensorial papillae. The outer surface of the oral sucker is spiny and spines are bigger, sharp with sensory receptors in their posterior edge. Tubercles with spines or receptors are more concentrated in the middle region and in one of the margins of the gynaecophoric canal. An excretory pore-like structure in the posterior portion was observed. The gynaecophoric canal has few sensory structures, spines broadned in their mid-region and are sharp pointed at the distal end. It was concluded that the presently studied characters are similar to those previously reported.

Key words: Schistosoma mansoni - adult male - morphology - scanning electron microscopy

The improvement of high resolution apparatus has permitted the detailed study of some structures so far overlooked. Through the scanning electron microscopy (SEM), the descriptive analysis of Schistosoma mansoni Sambon, 1907 adult worms was achieved. Thus, it was demonstrated that small spines cover the inner surface of the oral and ventral suckers, while the outer surface lacks these structures (Silk et al. 1969, Race et al. 1971). The inner surface of the ventral sucker presents sensorial papillae and a marginal ring of bigger spines (Hockley 1973).

On the dorsal surface of adult male worms there are tubercles randomly distributed along the body: more numerous at the middle region than at the anterior and caudal portions and less numerous toward the lateral and posterior margins of dorsal surface (Hockley 1973). The surface of the worms

\footnotetext{
${ }^{1}$ FAPERJ fellow (01/94-06/95); ${ }^{2} \mathrm{CNPq}$ research fellows, Proc. no 521431/95-6 and 303124/89-0

${ }^{+}$Corresponding author. Fax:+55-21-204.2343

Received 16 April 1997

Accepted 30 June 1997
}

is strongly wrinkled and between the folds and the tubercles there are numerous grooves, that in sections appear as a great number of sinuous, deep, branched and interconnected canals (LópezAlvarez 1980). Between the grooves there are spines and sensorial papillae.

The ventral surface is distinguished by the formation of the gynaecophoric canal with lateral margins covered by numerous and big spines, suggesting that these structures are related to the mating of the worms (Miller et al. 1972). The interior of this canal is also grooved, with little spines, irregularly distributed (Hockley 1973). The sensorial papillae of the surface of adult male worms are present all over the body and are, also, more numerous in the anterior region of the gynaecophoric canal (Morris \& Threadgold 1967, Silk et al. 1969, Smith et al. 1969).

The morphological features of the tegument in adult male worms are similar when the specimens are recovered from albino mice (McLaren \& Hockley 1977) hamsters (Miegeville et al. 1978) or after their development in vitro (Basch \& Basch 1982). Nevertheless, maturation of the tegument in the permissive host (mouse and hamster) is ex- 
pressed by the fusion of a superficial net, in small grooves and tubercles covered with spines, while in a non-permissive host (albino rat) the maturation is delayed and the tubercles are spineless (Senft et al. 1978) or are covered with a few spines (McLaren 1980).

In Brazil, there is not a great amount of data on SEM applied to the studies of schistosomiasis.

López-Alvarez (1980) and Kohn et al. (1982) verified that the antischistosomal oxamniquine induced morphological changes in the surface of adult worms. Similarly, modifications of tegument can be observed depending on the culture medium used during incubation (Kalaphothakis et al. 1988).

Based on the literature, papers dealing with descriptive analysis of $S$. mansoni adult male worms were published up to the 1980s. Due to the lack of actual data on this subject, a morphological study of Brazilian samples of S. mansoni by means of SEM is presented herein.

\section{MATERIALS AND METHODS}

Studied worms - The source and isolation conditions were those as described elsewhere (Machado-Silva et al. 1995).

Processing of specimens - Worms were fixed in AFA solution (acetic-formaldehyde-alcohol) and processed for SEM studies, according to Lanfredi et al. (1995). The fixed specimens were dehydrated in an ethanol series $\left(50-100^{\circ} \mathrm{GL}\right)$, critical point dried by $\mathrm{CO}_{2}$, coated with sputtering gold and examined under a scan electron microscope, Zeiss 904 and Zeiss 962 and photomicrographs obtained with a Neopan SS120 film.

Descriptive analysis - Each mesh contained 4 to 8 specimens of which the following characteristics were studied: (a) anterior region - between the oral sucker and the proximal portion of gynecophoral canal, aspects related to the outer and inner regions of oral and ventral suckers were considered; (b) middle and posterior region - the ventral portion, represented by the interior of the gynaecophoric canal, was analyzed in the anterior, middle and posterior regions and the spines and the sensorial papillae were characterized. The dorsal surface was studied in its ventral and dorsal regions mainly focusing the aspect of the tubercles, spines and sensorial papillae.

Terms used - The term strain refers to those worms obtained after several passages under laboratory conditions and sample to those originated from a recent isolation procedure.

\section{RESULTS}

Anterior region - This area was occupied by the oral and ventral suckers, the latter bigger and more prominent than the former. Both surfaces at this site did not present spines (Fig. 1). The oral sucker, oval, showed three very outstanding regions: an anterior, larger portion, another posterior, both covered with sharp spines varying in size and at the bottom, the oral cavity (Fig. 1). The anterior border of the oral sucker presented an area covered by small sharp spines and another spineless (Fig. 2). Conversely, the posterior border presented besides the spines, sensorial papillae (nonciliate) situated at a spineless site, where the tegument shows to be porous (Fig. 3).

The extremity of the ventral sucker presents two spiny regions and one, porous, spineless, where some sensorial papillae were observed. These papillae were distributed between the two rows of spines.

Middle region - Ventral: just behind the ventral sucker the body increases in width and folds ventrally to form the gynaecophoric canal. The proximal end of the canal was characterized as presenting a few tubercles, lack of spines and possessing the genital pore. The genital aperture is small, rounded, situated at the opposite side of that presenting greater number of tubercles of the dorsal region (Fig. 4). Sometimes, the genital pore appeared surrounded by filamentous material (Fig. 5). Protruding from the genital pore a cirrus-like structure, also covered with the above referred material was observed (Fig. 6). The tegument around the genital pore is porous, spineless, also lacking sensorial receptors. Along the canal (anterior, middle and posterior regions) more slender spines were observed (Figs 7,9) and others, short and pointless present in the middle region (Fig. 10). Besides the aspect of spines, differences were detected, related to the tegument which is more porous in the anterior and middle regions (Fig. 8) and to the localization of sensorial papillae. The middle and distal portions of the canal presented more sensorial papillae, that were either ciliate (Fig. 11) or non-ciliate (Fig. 12).

Dorsal region - The surface at the region of the suckers is smooth, the first spiny tubercles arising slightly posterior to the beginning of the gynaecophoric canal of which one of the dorsal margins is spiny whereas the other is smooth. One of the margins of canal presents a greater amount of tubercles, almost reaching the outer border, compared to the other in which the spines prevailed (Fig. 13). The border with the greater number of tubercles, overlaps the area with more spines (Fig. 13). The canal borders in the posterior region present a smaller number of tubercles (Fig. 16).

The dorsal tegument situated near the gynaecophoric canal, presented tubercles with numerous spines or they are located near those tubercles. The dorsal and lateral tegument is distin- 


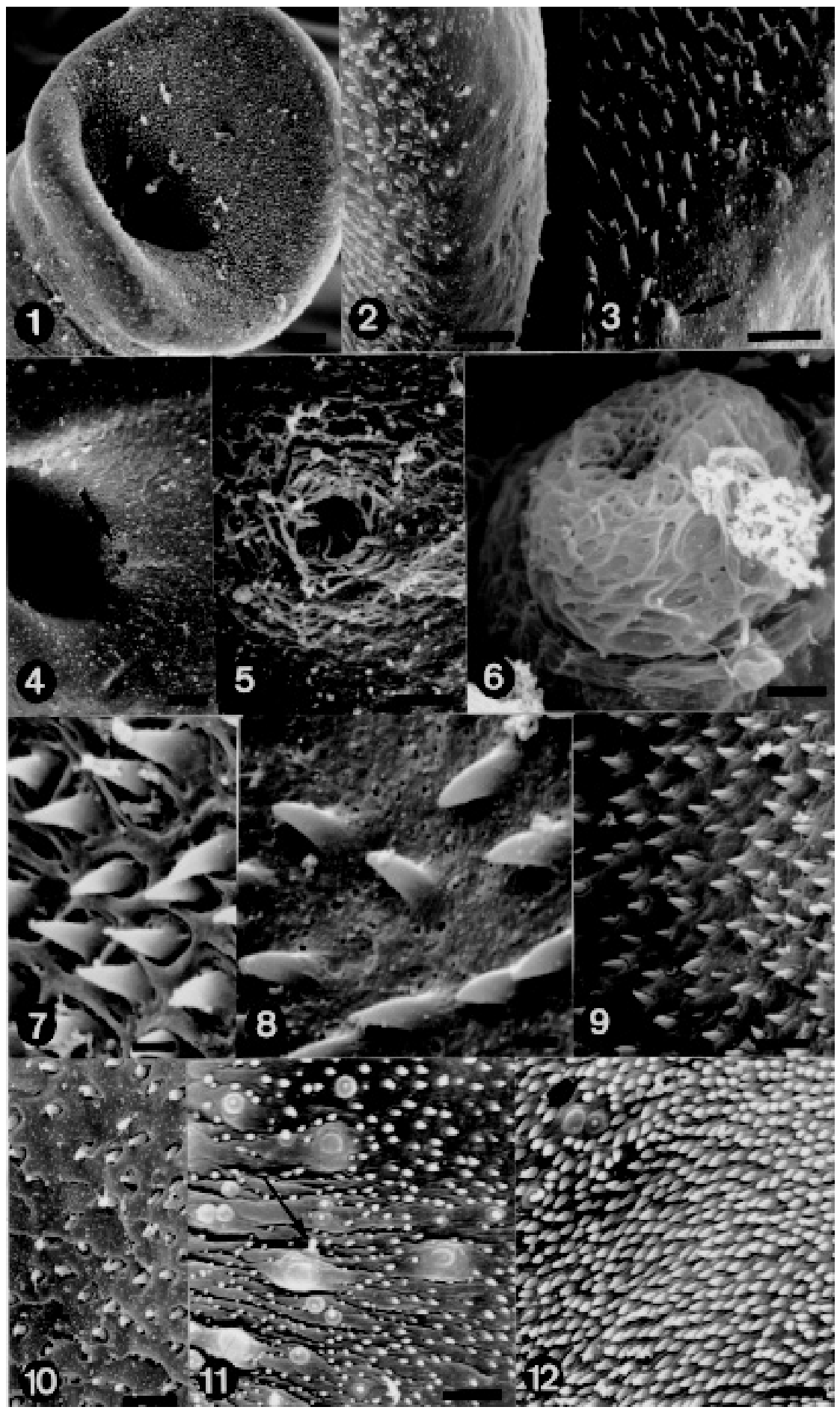

Schistosoma mansoni scanning electron photomicrographs of the tegument. Anterior region - Fig. 1: superior and inferior borders of the oral sucker. Bar $=20 \mu \mathrm{m}$. Fig. 2: spines of the oral sucker. Bar $=5 \mu \mathrm{m}$. Fig. 3: spines and ciliate and non-ciliate sensorial papillae (arrows) of the inferior border of the oral sucker. Bar $=5 \mu \mathrm{m}$. Middle region - Fig. 4: genital pore ( $\operatorname{arrow})$. Bar $=20 \mu \mathrm{m}$. Fig. 5: higher magnification of the genital pore. Bar $=5 \mu \mathrm{m}$. Fig. 6 : cirrus. Bar $=5 \mu \mathrm{m}$. Fig. 7: spines of the anterior portion of the gynaecophoric canal. Bar $=1 \mu \mathrm{m}$. Fig. 8: spines of the middle portion of the gynaecophoric canal, showing porous tegument. Bar $=1 \mu \mathrm{m}$. Figs 9 and 10: middle portion of the gynaecophoric canal, showing slender spines. Bar $=5 \mu \mathrm{m}$. Posterior region - Fig. 11 : posterior portion of the gynaecophoric canal, showing ciliate papillae (arrow). Bar $=5 \mu \mathrm{m}$. Fig. 12: posterior portion of the gynaecophoric, showing non-ciliate papillae (arrow). Bar $=5 \mu \mathrm{m}$. 


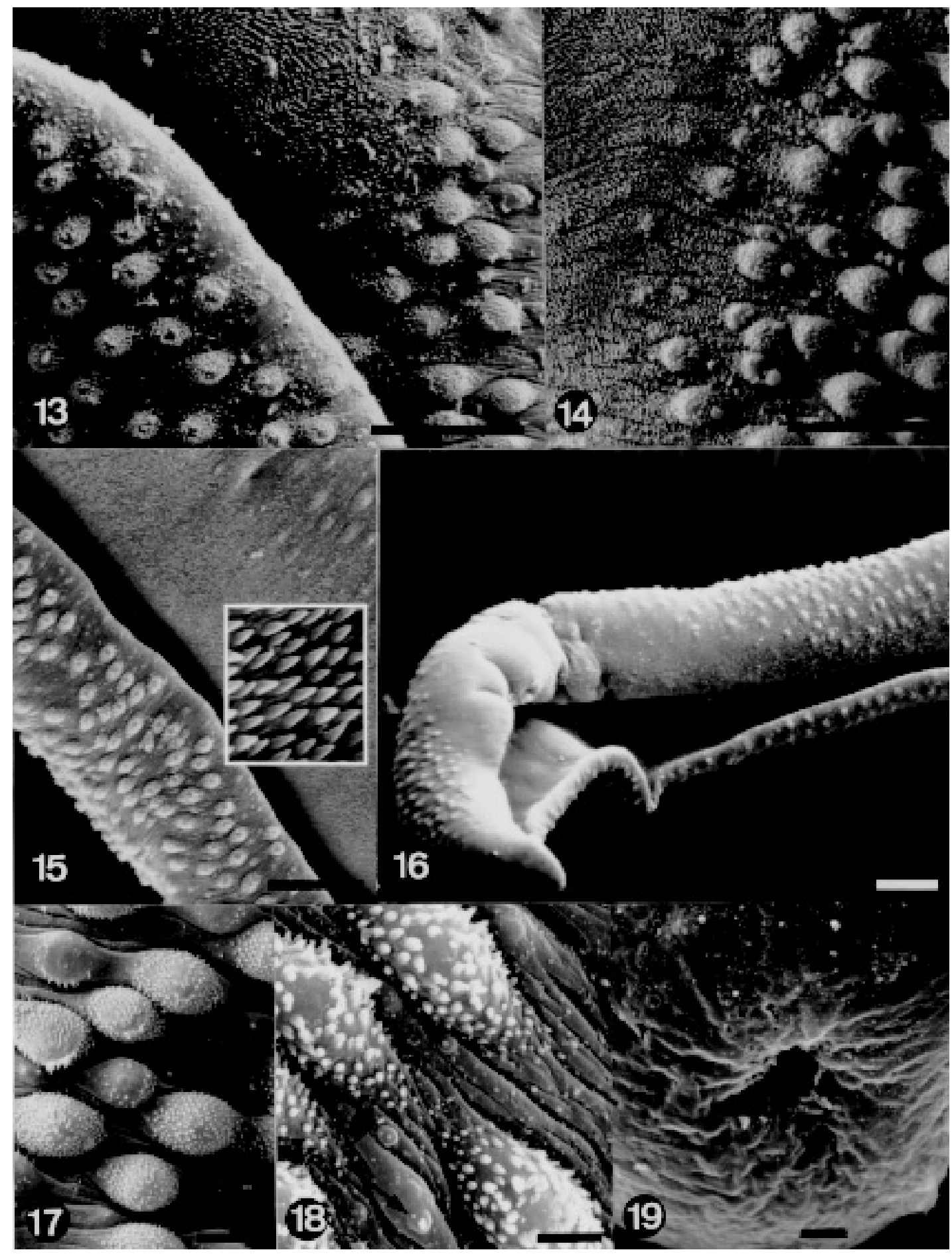

Schistosoma mansoni scanning electron photomicrographs of the tegument. Middle region - Fig. 13: difference between the borders of the gynaecophoric canal. Bar $=50 \mu \mathrm{m}$. Fig. 14: limit between a tubercles spiny area and a spiny area on the dorsal tegument. Bar $=50 \mu \mathrm{m}$. Fig. 15: borders of the gynaecophoric canal. Bar $=5 \mu \mathrm{m}$. Higher magnification square 3000X. Fig. 16: differences in the distributions of tubercles between middle and posterior regions. Bar $=100 \mu \mathrm{m}$. Fig. 17: tubercles with spines, "crab shell-like". Bar $=65 \mu \mathrm{m}$. Fig. 18: ciliate and non-ciliate sensorial papillae (arrows). Bar = $5 \mu \mathrm{m}$. Posterior region - Fig. 19: excrectory pore. Bar $=2 \mu \mathrm{m}$. 
guished by the presence of large tubercles and spines (Figs 14, 15). These large tubercles with a "crab shell-like" aspect were spiny or not and when present, the spines were randomly distributed along the body. The tegument surrounding the tubercles looked wrinkled (Fig. 17). The posterior region presented a lower concentration of tubercles than the anterior and middle regions. The sensorial papillae ciliate or non-ciliate were present on spineless tubercles or surrounded only by spines (Fig. 18).

Posterior region - Unlike the other regions of the tegument, the distal extremity showed neither tubercles nor spines. In this area, in a depression of the tegument the excretory pore, with a "volcano gate-like" aspect, was observed. The tegument around this site is also porous (Fig. 19).

\section{DISCUSSION}

Anterior region - The tegument of $S$. mansoni is an important interface between the parasite and its intravascular environment in the host. Through this specialized tegument, adult worms perform three basic activities for their survival: assimilate blood nutrients from the host are able to escape from the immune response of the host against their presence (McLaren 1980, Kalapothakis et al. 1988, Abath \& Werkhavser 1996) and regenerate from induced lesions (Popiel et al. 1985). Although the tegument presents a nutritional absorptive activity, it seems that this function is more effective when the buccal cavity, situated inside the oral sucker, is involved in the process (Hockley 1973). It is accepted that the spines on the borders of the oral sucker have the function of attaching the helminth and scraping the tissues of the blood vessel walls (Miller et al. 1972, Kruatrachue et al. 1979).

The studied specimens present the superior and inferior borders of the oral sucker covered with spines (Fig. 1). These features are in agreement with previously reported descriptions (Silk et al. 1970, Race et al. 1971, Miller et al. 1972). Conversely, the function of the ventral sucker is more related to the displacement of the specimen, considering that this structure is bigger than the oral sucker and with sensorial papillae that are mechano-receptor structures (Hockley 1973). The morphological characteristics of the ventral sucker in the specimens studied herein also ratify reported data on S. mansoni (Hockley 1973, McLaren 1980) and S. curassoni Brumpt, 1931 (Probert \& Awad 1987).

Middle region - Unlike the anterior region, the middle region presents a wide range of spines distribution on the ventral and dorsal surfaces of the body of the schistosome (Fig. 15). These morphological findings agree with those obtained in Brazil (López-Alvarez 1980, Kohn et al. 1982) and overseas (Miller et al. 1972). The present report on the localization of the genital pore at the entrance of the gynaecophoric canal (Fig. 4) is in accordance with other studies related to the $S$. mansoni (Silk et al. 1970, Race et al. 1971, Hockley 1973, Basch \& Basch 1982) and to the S. nasale Rao, 1933 (Southgate et al. 1990).

A more detailed study of the ventral surface revealed some aspects not referred yet: (1) the genital pore can appear surrounded by filamentous material (Fig. 5) that is also present nearby this pore and absent in other areas a little more apart from it; (2) a structure was identified as the cirrus, since it was arising from the genital pore with the same filamentous material observed around the gonopore (Fig. 6). Few are the data on the ultrastructural aspects of the reproductive system of $S$. mansoni. Thus, the morphology of the cirrus can be compared with the description of this structure as it appears in Prosthodendrium volaticum Blankespoor \& Ulmer, 1972 (Kessel \& Shih 1976).

The absence of a cirrus in the $S$. mansoni has been emphasized by several authors based on either light microscopy studies (Travassos et al. 1969, Kastner et al. 1975) or electron microscopy (Kitajima et al. 1976). The latter referred authors considered that during the mating period of adult worms, there is a continuous process of sperm flow inside the gynaecophoric canal, making easier the fertilization of the females. Nevertheless, we consider that the cirrus may improve this process and, perhaps, for this reason a specimen could present a small number of testes, as we observed during studies under light microscope (Machado-Silva et al. 1995).

Moreover, it is known that the $S$. mansoni evolved from a hermaphrodite ancestor (Popiel 1986 , Basch 1990) with a further adaptation in rodents (Combes 1990).

An interesting finding is related to the presence of the cirrus in a specimen recovered from a naturally infected $N$. squamipes (SN sample). Erasmus (1986) has demonstrated that heterogametic dimorphism can be on account of the parasite strain in the interaction with the host. An association of these facts depends on further investigations. Some reported data indicate that the anterior portion of the gynaecophoric canal presents small, not pointed spines (Miller et al. 1972, McLaren 1980, Basch $\&$ Basch 1982). Nevertheless, we verified that the far anterior region of the canal is spineless and that there is a gradual increase in the number of spines in this same anterior region. Besides, these spines are sharp.

McLaren (1980) reports that the tegument in the anterior region is porous, with the presence of numerous sensorial structures, possibly related to 
the genital pore. The specimens analyzed herein, although showing a porous tegument, did not present any sensorial structure at this site.

The sensorial papillae were observed in higher concentrations in the middle and posterior regions of the gynaecophoric canal, unlikely it has been previously reported (Morris \& Threadgold 1967, Silk et al. 1969). The aspect of the porous tegument, the spines with different sizes, the sensorial papillae ciliate or non-ciliate (Figs 11, 12) present similar characteristcs to those referred by other authors (Hockley 1973, McLaren 1980).

When adult worms reach sexual maturity, the lateral extremities of the body bend, one over the other, from the right side to the left or vice-versa, forming the gynaecophoric canal (McLaren 1980). However, our data have demonstrated that the right side (with more spines) remains under the other with more tubercles (Figs 13, 15).

The topographic aspects of the dorso-lateral tegument were in accordance to previous reports (Silk et al. 1970, Hockley 1973, McLaren 1980).

Posterior region - It was observed that the posterior region is devoid of tubercles (Fig. 19), that the excretory pore is at the distal extremity and that the tegument is porous. These features have also been referred elsewhere (Silk et al. 1970, Miegeville et al. 1978).

Permissiveness of $N$. squamipes - Mice and hamsters are considered permissive hosts while the albino rat is a non-permissive host (Senft et al. 1978). Besides, it has been demonstrated that the presence of spines on the tegument of adult specimens also depends on their age and physiological conditions (Southgate et al. 1990).

Data obtained herein, based on the analysis of the $S$. mansoni by SEM, rectify those obtained by means of light microscopy, when $N$. squamipes was considered a permissive host. Some aspects must be considered for comparison of data from albino mice (Silk et al. 1970, Race et al. 1971, Hockley 1973): in the specimens recovered from naturally infected rodents (SN sample), those aspects are related to the oral sucker (Fig. 1), the distribution and morphological characteristics of the spines and sensorial papillae, the dorsal tegument with wrinkled appearance, presenting ciliate and nonciliate sensorial papillae and the tubercles with numerous spines (Fig. 18). This later character is absent in specimens revovered from non-permissive hosts, like the albino rat (McLaren 1980).

\section{ACKNOWLEDGMENTS}

To Dr Roberto Magalhães Pinto, Departamento de Helmintologia, Instituto Oswaldo Cruz, for critical review and translation of the text; to Genilton José Vieira for his technical help in the photomicrographies.

\section{REFERENCES}

Abath FGC, Werkhauser RC 1996. The tegument of Schistosoma mansoni: functional and immunological features. Parasite Immunol 18: 15-20.

Basch PF 1990. Why do schistosomes have separate sexes? Parasitol Today 6: 161-163.

Basch PF, Basch N 1982. Schistosoma mansoni: scanning electron microscopy of schistosomula, adults and eggs grown "in vitro". Parasitology 85: 333338.

Combes C 1990. Where do human schistosomes come from? An evolutionary approach. Trends Ecol Evol 5: 334-336.

Erasmus DA 1986. Structural and metabolic changes in female Schistosoma mansoni following male stimulation. J Chem Ecol 12: 1755-1764.

Hockley DJ 1973. Ultrastructure of the tegument of Schistosoma. Adv Parasitol 11: 233-305.

Kalapothakis E, Hirst E, Evans WH 1988. Pertubations of the topography of the tegument of adult Schistosoma mansoni. A scanning electron microscope study. Braz J Med Biol Res 21: 961-969.

Kastner MRQ, Kohn A, Teixeira ED, Pitanga LC 1975. Estudo morfológico do Schistosoma mansoni Sambon, 1907 encontrado na espécie humana. Rev Soc Bras Med Trop 9: 247-261.

Kessel RG, Shih CY 1976. La microscopia electrónica de barrido en Biologia. Atlas de Organización Biológica para Estudiantes. Editorial Dossat SA, España, $351 \mathrm{pp}$.

Kitajima EW, Paraense WL, Corrêa LR 1976. The fine structure of Schistosoma mansoni sperm (Trematoda: Digenea). J Parasitol 62: 215-221.

Kohn A, López-Alvarez ML, Katz N 1982. Transmission and scanning electron microoscopical studies in the tegument of male Schistosoma mansoni after oxamniquine treatment. Ann Parasit Hum Comp 57: 285-291.

Kruatrachue M, Upatham ES, Sahaphong S, Riengrojpitak S 1979. Scanning and transmission electronmicroscopy of Mekong Schistosoma eggs and adults. S Asian J Trop Med Publ Hlth 10: 85-96.

Lanfredi RM, De Souza W, Gomes DC 1995. Comparative study of four species of Trichuris Roederer, 1761 (Nematoda, Trichurinae) by scannig electron microscopy. Mem Inst Oswaldo Cruz 90: 489-496.

López-Alvarez ML 1980. Contribuição ao estudo ultra-estrutural do Schistosoma mansoni Sambon, 1907. MSc Thesis, Departamento de Histologia e Embriologia, UFRJ, 93 pp.

Machado-Silva JR, Galvão C, Oliveira RMF, Presgrave OAF, Gomes DC 1995. Schistosoma mansoni Sambon, 1907: Comparative morphological studies of some Brazilian strains. Rev Inst Med Trop São Paulo 37: 441-447.

McLaren DJ 1980. Schistosoma mansoni: The parasite surface in relation to host immunity. John Willey \& Sons, Ltd., England, 229 pp.

McLaren DJ, Hockley DJ 1977. Blood flukes have a double outer membrane. Nature 269: 147-149.

Miegeville M, Marjolet M, Vermeil C 1978. Observations de Schistosoma mansoni en microscopie 
électronique à balayage. C R Acad Sci (Paris) 286: 901-903.

Miller FH, Tulloch GS, Kuntz RE 1972. Scanning electron microscopy of integumental surface of Schistosoma mansoni. J Parasitol 58: 693-698.

Morris GP, Threadgold LT 1967. Ultrastructure of the tegument of adult Schistosoma mansoni. J Parasitol 54: 15-27.

Popiel I 1986. Male-stimulated female maturation in Schistosoma: A review. J Chem Ecol 12: 1745-1754.

Popiel I, Irving DL, Basch PF 1985. Wound healing in the trematode Schistosoma. Tissue Cell 17: 69-77.

Probert AJ, Awad AHH 1987. Scanning electron microscopy of the tegument of adult $S$. margrebowiei Le Roux, 1933 with particular reference to the structure of the tubercles. Parasitology 95: 491-498.

Race GJ, Martin JH, Moore DV, Larsh Jr JE 1971. Scanning and transmission electronmicroscopy of Schistosoma mansoni eggs, cercariae and adults. Am J Trop Med Hyg 20: 914-927.
Senft AW, Gibler WB, Knopf PM 1978. Scanning electron microscope observations on tegument maturation in Schistosoma mansoni grown in permissive and non-permissive hosts. Am J Trop Med Hyg 27: 258-266.

Silk MH, Spence IM, Gear JHS 1969. Ultrastructural studies of the blood fluke Schistosoma mansoni. I The integument. S Afr J med Sci 34: 1-10.

Silk MH, Spence IM, Buch B 1970. Observations of Schistosoma mansoni blood flukes in the scanning electron microscope. S Afr J med Sci 35: 23-29.

Smith JH, Reynolds ES, Lichttenberg F von 1969. The integument of Schistosoma mansoni. Am J Trop Med Hyg 18: 28-49.

Southgate VR, Rollinson D, De Bont J, Vercruysse J, Van Aken D, Spratt J 1990. Surface topography of the tegument of adult Schistosoma nasale Rao, 1933 from Sri Lanka. System Parasitol 16: 139-147.

Travassos L, Freitas JF, Kohn A 1969. Trematódeos do Brasil. Mem Inst Oswaldo Cruz, 67: 1-887. 